\title{
Pharma scrambles to fast-track drugs
}

\author{
'Breakthrough therapy' status is much sought after, but \\ there is confusion about its definition and impact.
}

\section{BY HEIDI LEDFORD}

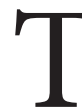
The experimental cancer drug ibrutinib has wowed in clinical trials, beating deadly blood cancers without the painful side effects of currently approved therapies. And it has raced through development and regulatory hurdles, in part thanks to a US programme to accelerate the development of particularly promising drugs, says its developer Pharmacyclics, based in Sunnyvale, California.

The US Food and Drug Administration (FDA) launched the 'breakthrough therapy' designation in 2012, and the label has been eagerly embraced by the pharmaceutical industry. Recent months have seen a steady stream of drugs being submitted for review. For some firms - particularly young ones - the designation can bring an extra boost of cash by raising investor confidence.

But for all the fanfare, the industry is also watching closely to see exactly what benefits can be gained by having a drug reviewed through this route. "It's like winning a beauty pageant," says Timothy Coté, a former director of the FDA's Office of Orphan Products Development who now runs a consultancy called Coté Orphan Consulting in Silver Spring, Maryland. "It doesn't have specific tangible outcomes, but it does appear to have enlivened the community."

The breakthrough therapy designation was created by the FDA Safety and Innovation Act, a law that requires the agency to fast-track promising drugs for serious or life-threatening conditions. The FDA aims to do this by meeting early and often with developers, as well as working with them to design clinical trials that deliver the needed data quickly and efficiently.

The industry leapt on the opportunity, so far submitting 99 applications for the designation. But the flurry of applications may partly be a product of confusion, says Coté: the FDA has avoided laying out detailed descriptions of what constitutes a breakthrough, and some companies are unsure of the criteria. "Most biotech chief executives with something in the clinic think that they're already there," Coté says - but 47 of the applications submitted in the past year have been denied. In most cases the denials are due to insufficient clinical data, the FDA says.

Although the lack of clear guidelines could be deemed confusing, the FDA's avoidance of hard-and-fast criteria can actually be an advantage for some drugs, says Keith Flaherty, an oncologist at Massachusetts General Hospital in Boston. He was pleased, for example, to see the FDA bestow breakthrough status on a melanoma therapy called lambrolizumab. The drug, which is made by Merck (based in Whitehouse Station, New Jersey), is one of several in development that stimulate the immune system to fight cancer by blocking a protein called PD1. Lambrolizumab works in only about $38 \%$ of patients, which is well below the response rate for some other cancer drugs in development. However, doctors champion it because it has tolerable side effects and can yield unusually long-lasting responses. "Having it get that designation really put a
"The FDA has avoided detailed description of what constitutes a breakthrough." spring in the step of many people in our community," says Flaherty. "It showed us that the FDA really gets the importance of these drugs."

There are lingering concerns that other aspects of the drug-development process might delay the ultimate impact of the breakthrough-designated compounds. Jeff Allen, executive director of the patientadvocacy group Friends of Cancer Research in Washington DC, notes that drugs are increasingly developed alongside medical tests that will select the patients who are most likely to benefit from them. The new law does not address the development of such tests, but unless their evaluation and approval is accelerated, a breakthrough drug - even if approved - may not achieve its full potential in the clinic, he says.

Coté, despite being a fan of the programme, says that it might not have much of an impact on review times because the FDA has always prioritized promising applications. The biggest benefit, says Steven Grossman, founder of the consultancy HPS Group in Silver Spring, might be for small companies that can use the designation to get the FDA's attention earlier in development than they normally might.

Financial analysts expect ibrutinib to be approved by the end of the year, and Coté thinks that most of the breakthrough designees will ultimately prevail. "If the FDA likes what you're doing, that can't be a bad thing," he says. - 